Towards the end of the report a list is given of nearly 200 papers published by members of the staff during October 1958-September 1959. In the notes which deal with staff matters, reference is made to the fact that in 1959 Prof. R. G. Baskett took up his appointment as director of the Institute, and a brief but well-deserved reference is made to the retirement of Dr. A. T. R. Mattick, who has served the Institute and the dairy industry with distinction for some forty years.

J. A. B. SмrтH

\title{
NEW AMERICAN OBSERVATORIES
}

$I^{N}$ $\mathrm{N}$ order to make astronomical research facilities available to those many universities which cannot themselves afford the necessary expensive equipment, the National Science Foundation is providing financial support for the construction of two major observatories, the National Radio Astronomy Observatory at Green Bank, and the Kitt Peak National Observ. atory near Tucson, Arizona.

Green Bank, in Deer Creek Valley, West Virginia, is at an elevation of $2,600 \mathrm{ft}$., ringed by mountains rising to 4,000 $\mathrm{ft}$., effectively shielding the site from man-made radio noise. The climate is mild, and there are no high winds which would make operation of a large radio telescope difficult. An $85-\mathrm{ft}$. telescope was brought into operation in October 1958, and since then construction of a 140-ft. telescope, laboratories, residences and workshops has been under way. The reflecting surface of the 85 -ft. telescope, made of aluminium sheet, is accurate to 1 in. and operates down to wave-lengths as short as $3.5 \mathrm{~cm}$., at which the telescope beam width is $7 \mathrm{~min}$. of arc. Both telescopes are on equatorial mountings. The moving mass of the $140-\mathrm{ft}$. telescope will exceed 2,000 tons, yet it will be capable of being steered with a precision of a fraction of a minute of arc and will also have a surface accurate to 1 in. In addition to other small telescopes there is a horn $120 \mathrm{ft}$. long ; the energy which this collects can be calculated from its dimensions and it is fixed so that it can observe the radio source in Cassiopeia each day, thus providing a standard calibration source in the sky available to many radio astronomers. A variety of receivers covering the wave-length range of $3 \cdot 75-$ $75 \mathrm{~cm}$. is available, and three separate receivers working on different wave-lengths can be used simultaneously on the 85-ft. telescope. Besides being displayed on the chart of a pen recorder, the receiver outputs are digitized together with telescope position and time. Extensive use of digital computer techniques is already being made in analysing and reducing the observations.

Among the first observations made at the National Radio Astronomy Observatory were a study of the radio emissions from Jupiter and a survey of the central regions of the Galaxy at a wave-length of $3.75 \mathrm{~cm}$. showing remarkable detailed structure. In addition, studies are being made of planetary nebulæ and ionized hydrogen clouds, supernovæ remnants and peculiar galaxies.

Three years were devoted to testing the seeing conditions at a number of places before Kitt Peak was chosen as the site for the National Observatory in March 1958. An agreement with the Papagos Indians (who call astronomers "the People with the Long Eyes") leased 200 acres to the Observatory, and construction of an 80-in. telescope is under way. This will have a coudé focus as well as prime and cassegrain, and will be equipped for direct photography, photoelectric photometry and spectroscopy. There is also a 36-in. telescope with a cassegrain spectrograph, and two 16-in. telescopes which will be used for bright star work. The University of Arizona is also moving a 36-in. telescope to the site.

On Kitt Peak there will be an optical workshop with some of the best testing facilities in the world, together with an office and laboratory building, dining hall and dormitory, houses and a shop. But the headquarters are adjacent to the University of Arizona in Tucson, and the staff and visiting astronomers will spend most of their time in the research offices there.

It has recently been decided to build a large solar telescope on Kitt Peak. The heliostat will have an 80-in. plane mirror feeding a 60 -in., 300-ft. focal length concave mirror at the bottom of a tunnel $500 \mathrm{ft}$. long. The image of the Sun, $34 \mathrm{in}$. in diameter, will be reflected on to the slit of a large vacuum spectrograph. The outside of the building will be maintained at ambient temperature to prevent disturbing convection currents.

The National Observatory and the National Radio Astronomy Observatory will be valuable additions to the research facilities of universities which could not, alone, have provided them.

V. C. REDDISH

\section{BIOLOGICAL EFFECTS OF EXPOSURE TO INTENSE RADIATION}

\begin{abstract}
A UNIQUE and important experiment to determ ine the biological effects of acute and highlevel radiation exposure has recently been completed under the auspices of the International Atomic Energy Agency at the Boris Kidrich Institute at Vinca, near Belgrade, Yugoslavia. Details of the experiment were given at a press conference held at Vinca on April 27 by the international team of
\end{abstract}

scientists responsible for its organization and execution, and a brief report of the experiment and the conference is published in the International Atomic Energy Agency Bulletin, 2, No. 3, 3 (July 1960).

It will be recalled that on October 15,1958 , during an accident to the nuclear reactor $R B$ at the Institute, six persons in the immediate vicinity of the unshielded 